circumstances for observation on more than one occasion, yet entirely escaping detection, so that the mere fact of a single observer only having seen a comet, is hardly a sufficient argument against its existence. The late Prof. d'Arrest even thought it worth while to submit the re. puted observations of the D'Angos-Comet of 1784 to further calculation, notwithstanding Encke's well-known investigation in the "Correspondance Astronomique" of the Baron de $\mathrm{Zach}$, and we may have something to say on this subject in a future column. Not having seen any reference to "Stark's comet" in English astronomical works, we have given the particulars recorded of it here.

THE GREAT COMET OF I843.-. There was some doubt at the time, from the difficulty attending the determination of the orbit of this extraordinary body upon the European observations, whether it had transited the sun's disc on the day of perihelion or not. The defnitive orbit calculated by a most complete investigation by the late Prof. Hubbard, of Washington, shows that a transit did actually take place on the evening of February 27, Greenwich time, and might have been observed in Australia. In next wcek's "Astronomical Column" we shall give the particulars of this interesting phenomenon, and reproduce Hubbard's elements with some inferences drawn from them.

D'ARREST'S COMET IN I 877.-The mean motion of this comet at the last appearance in 1870 , determined by $M$. Leveau from an elaborate calculation of the perturbations in the two preceding revolutions, would bring this comet into perihelion again on April 17, 1877. The effect of planetary attraction in the present revolution being comparatively small, if we take this date for perihelion passage, the computed path is not likely to differ materially from the true one. It is as follows :-

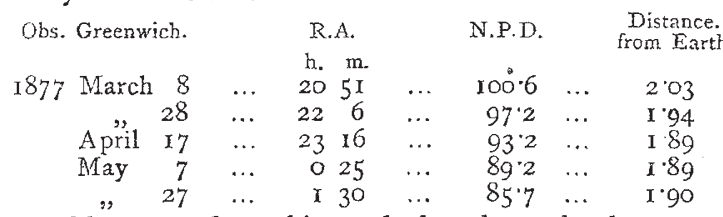

It would appear from this track that the only chances of observation will be with the aid of powerful telescopes in the southern hemisphere. At the last return the comet was excessively faint, and was only detected at a few of the European observatories.

\section{THE INTERNATIONAL GEOGRAPHICAL} EXHIBITION

THE idea of holding an International Geographical 1 Exhibition at Paris, the opening of which we announced last week, in connection with the Geographical Congress which opens in a day or two, was a happy one, and has so far been fruitful in results. The catalogue of articles exhibited covers about 450 octavo pages, and the daily number of visitors reaches thousands ; last Sunday it was I2,000, including the Sultan of Zanzibar, and other visitors of all ranks and classes of society. No better method could have been adopted of showing the advances made in geography in recent years; how from being a mere record of "hairbreadth 'scapes by flood and field," it has become a complicated science, or rather meetingground of all the sciences; for, as the equipment of and instructions to the English Arctic Expedition show, it requires the aid of all the sciences to do its work well, and in return carries contributions back to them all. We have no doubt that the great majority of the visitors to the Exhibition will be astonished that geography has so many and so varied apparatus and results to show, and we hope that the Exhibition and Congress will be the means of awakening in France, as well as in other countries, an increased interest in geography, lead to its being raised to a higher platform in education, and to its being taught in a more comprehensive and more scientific way than hitherto. No doubt this will be but the first of a series of such exhibitions and congresses, though probably not annual, and we hope that the next one will be held in London. We think they are well calculated to give a strong stimulus to the scientific study of geography.

The arrangements of the Paris Exhibition make it accessible to all classes, the price of admission in some cases being as low as a penny. The articles are arranged mainly according to countries, Britain occupying but a comparatively narrow space in the catalogue. While Russia has 42 pages, Sweden, Norway, and Denmark about 40, Holland 30, Austria and Hungary 44, Great Britain and her Colonies cover only 9 pages. Even Germany has only i2 pages allotted to her. These apparent anomalies no doubt arise from some imperfections in the preliminary arrangements, and are probably to be looked for in first attempts of this kind; no doubt the organisers of the next Geographical Exhibition will profit by the defects of the present, and have one complete all round.

As our readers are aware, the objects exhibited are classified into seven groups; an indication of what is included in each group will convey some idea of the nature of the objects exhibited, as well as of the comprehensive nature of modern geography.

Group I., Mathematical Geography, Geodesy, and Topography, includes of course instruments of practical geometry, surveying, topography, geodesy and astronomy ; tables of projection and calculation, maps according to the various systems of projection, sidereal maps, naps of triangulation, maps showing the curves of magnetic declination, \&c. In the second group, that of Hydrography and Maritime Geography, is included a great variety of instruments besides those used on board all sea-going ships; there are dredging and sounding apparatus with specimens of what is brought up from the sea-bottom, sounding thermometers and charts, and publications of various kinds. The third group is an interesting one; it includes Physical Geography, General Meteorology, General Geology, Botanical and Geological Geography, and General Anthropology. These are illustrated by in. struments used in the observation of the principal meteorological phenomena, by maps, atlases and globes representing the essential facts belonging to the domain of Physical Geography, Meteorology, and the other sciences referred to, as well as publications bearing upon them. In group IV., that of Historical Geography, History of Geography, Ethnography, and Philology, are included, works and MSS., ancient and modern, bearing on these subjects, ancient globes and maps, antiquated instruments, ethnographic collections, and dictionaries of geography.

As might be expected, the fifth group, Economic, Commercial, and Statistical Geography is a large and varied one; it includes works and maps bearing on population, agriculture, industry, commerce, ways of communication, ports, colonisation, emigration, \&c., plans and models of bridges, tunnels, railways, routes, telegraph lines; new apparatus for piercing rocks, manufactures or mineral objects peculiar to any country, collections of all kinds of commercial products, machinery used in manufactures of such products, produce and apparatus of deep-sea fishing, \&c. Group VI, Education and the Diffusion of Geography, includes of course works, maps, charts, globes, models and instruments of various kinds, and deserves the attention of all engaged in education. Group VII. comprehends Explorations, Scientific, Commercial, and Picturesque Voyages, and, as might be expected, includes a great variety of objects. There are astronomical, topographical, meteorological, and photographic instruments of various kinds; collections of every kind bearing on voyages of exploration, including cooking apparatus and drugs; native implements and 
weapons ; tents and boats of various kinds, special instruments and apparatus for polar expeditions, \&c., not to mention narratives and publications of every kind relating to voyages.

How varied the programme of this exhibition is will be seen from the above, as well as the fact that the geography of the present day is a very complicated and allembracing province of kriowledge indeed.

It is impossible here to analyse in detail the exhibits of each country; we can only at present refer to some of the objects which, as we learn from a correspondent, have attracted considerable attention.

The fine set of instruments for travellers exhibited by our Royal Geographical Society, and invented by Capt. Georges, R.N., seems to have excited considerable attention; it includes a doublé pocket sextant, an artificial horizon, and a barometer ; the latter especially, on account of its ingenious construction, making it useful in mountaineering, is said to have attracted the attention of the New French Alpine Club.

From Norway comes a very simple declimeter having a crank working on a small notched wheel which multiplies by ten the number of degrees on the limb on which the readings are taken; a close approximation can thus be obtained by a very simple contrivance.

A Russian marine officer has sent a compass magnificently fitted up, and a lead for taking soundings, and samples of the bottom in lakes and shallow seas. It was used with success on Ladoga, the Caspian, and the Baltic. The apparatus is very simple, cheap, and not ponderous.

Mohn's map of churches struck by lightning in Norway is exhibited in order to illustrate the special danger of lightning to churches. It shows that two churches in every three years are struck and one of the two is utterly clestroyed, and that in a climate where thunderstorms are relatively infrequent.

Sweden exhibits two wonderful pieces of apparatus. The first is a meteorograph for printing in numbers the degrees of dry and wet bulb thermometer, barometer, and the force of the wind. The types are placed on wheels which are moved every quarter of an hour by electricity, The barometer is a syphon one, and the thermometers open by the top a needle which descends every quarter of an hour into the mercury and gives the degree. The apparatus works regularly at the University of Upsal and at the Vienna. Observatory, where the readings have been found quite correct. The printed sheets obtained at Upsal are posted on the wall of the Geographical Exhibition.

A Swedish engineer has invented a machine to show where to find beds of iron ore, and to determine also the depth to which it is necessary to descend. The miracle is performed by tracing on a map isodynamic magnetic curves, with a compass exposed to the perturbating influence of a magnetic needle placed at a distance. Two systems of isodynamic curves are to be traced, and the distance between both centres is proved to indicate the depth. Experiments and explorations with this extraordinary instrument have proved successful.

The Belgian universal meteorograph, as used in Ghent, is said to be the great success of the Exhibition. It is expected to create a revolution in weather-warnings and in meteorology generally, and will leave the famous Greenwich registering apparatus far behind. A reading is taken every quarter of an hour and engraved on copper ready for going through the press. The inventor is $M$. Van Rysselberghe, Professor to the Navigation School of Ostend.

The members of the several juxies visited the galleries of the Exhibition on Monday last for the first time. Many members of the Academy of Science-MM. Leverrier, Faye, Quatrefages, and others-were present, as well as the foreign commissioners. We hope to give further details next week.

\section{THE REGULATION OF RIVERS}

$7 \mathrm{HE}$ recent disastrous floods in France and England call attention to the question whether it is practicable so to regulate the flow of the water in rivers as to prevent, or at least greatly diminish, such misfortunes for the future. Facts and numerical data exist which show that such regulation is practicable with much less difficulty and cost than would be thought by any one who had not made the necessary calculations.

It is perhaps scarcely necessary to say that the method of keeping the floods off the lands by means of embankments, which is the only possible resource when we have to contend against the sea or tidal rivers, is totally inapplicable to the case of the inundations of mountain streams like the Garonne. There need not be any difficulty as to the strength of the embankments, but it would be im practicable to make them high enough to contain between them such torrents as that of the Garonne when in flood. The only way in which mountain torrents can be regulated is by constructing reservoirs to retain the floodwater: and the more this plan is looked at, the more feasible it will appear.

We shall first refer to a paper by Charles Ellett, jun., C.E., on "the Physical Geography of the Mississippi Valley, with suggestions for the improvement of the navigation of the Ohio and other Rivers," forming part of the "Smithsonian Contributions to knowledge" for I85 r, published by the Smithsonian Institution, Washington.

This paper contains the tabulated results of an elaborate series of observations made by the author in the spring and summer of I 849 on the flow of the Ohio, at Wheeling, between Pittsburg and Cincinnati. The flow varied from $10,158,000$ cubic feet per hour, with a depth of 2.20 feet on the bar at Wheeling, to 736,000,000 cubic feet, with a depth of $3 r^{\circ} 25$ feet on the bar.

"The average volume of water annually flowing down the Ohio is $835,000,000,000$ (eight hundred and thirty-five thousand million) cubic feet. This volume would fill a lake 100 feet deep and $17 \frac{1}{3}$ miles square. To have regt1lated the supply of the river in 1848 , so as to have kept the depth on the bar at Wheeling uniform throughout the year, would have required reservoirs capable of holding $240,000,000,000$ cubic feet, which is equivalent to a single lake roo feet deep, and $9 \frac{1}{8}$ miles square. There is no difficulty, on any of the principal tributaries of the upper Ohio, in obtaining reservoirs capable of holding from twelve to twenty thousand millions of cubic feet. It can scarcely be doubted that twelve or fifteen sites for dams may be selected capacious enough to hold all the excess of water, and equalise the annual discharge so nearly that the depth may be kept within a very few feet of an invariable height."

To control the floods of the river, however, much less than this would be needed. Mr. Ellett takes the case of the flood of March I84I, as being that in which the greatest quantity of water passed down of all the floods concerning which he has information. He takes 25 feet of depth on the bar as the high-water mark, above which the river is in flood; he estimates that during nine days of flood the river passed down I 59,000,000,000 cubic feet of water, while during the same time, had it been steady at the high-water mark, the discharge would have been only I I $5,000,000,000$. If consequently the excess of 44,000,000,000 had been kept back in reservoirs, the flood would have been prevented.

The volume it is here proposed to deal with$44,000,000,000$ cubic feet-is "just equal to the quantuty the river would discharge in fifty days when there is a deptb of tive feet in the channel."

The valley of the upper Alleghany, one of the tributaries of the Ohio, is about a third of a mile in width. A dam from 55 to 60 feet in height, thrown across the trough of this valley, so as to submerge not only the main 